\title{
"I'm Not Really Afraid of Osama Bin Laden!" Fear of Terrorism in Dutch Children
}

\author{
Peter Muris · Birgit Mayer · Sandra van Eijk • \\ Marit van Dongen
}

Published online: 11 December 2007

(C) The Author(s) 2007

\begin{abstract}
We examined to what extent children in The Netherlands are affected by the threat of terrorism. For this purpose, a sample of school children living in Rotterdam or adjacent satellites $(N=216)$ completed a fear survey that included a number of terrorism-related items, and were confronted with ambiguous vignettes to measure threat-related interpretation bias. The results demonstrated that although a number of terrorism-related items (i.e., bombing attacks, explosions in a bus or subway) listed high in a ranking of most intense childhood fears, very few children made terrorist-related interpretations of ambiguous situations.
\end{abstract}

Keywords Fear of terrorism - Children · Interpretation bias

\section{Introduction}

Fears are quite prevalent among normal children (Gullone 2000). More precisely, research employing standardized fear questionnaires has indicated that many children report a surprisingly large number of fears. In most cases, these fears are concerned with dangerous situations and physical harm, including burglars breaking into the house, falling from a high place, or being hit by a car or truck. Due to changes in society, youths are increasingly confronted with "new" threatening stimuli and situations: school violence, sexual assaults, domestic violence, parental divorce, abuse, and neglect are real-life threats for a growing number of children and adolescents (e.g., Fishkin et al. 1997). In addition, television makes youths

\footnotetext{
P. Muris $(\bowtie)$

Institute of Psychology, Erasmus University Rotterdam, Woudestein T13-37, P.O. Box 1738, 3000 DR Rotterdam, The Netherlands

e-mail: muris@fsw.eur.nl

B. Mayer - S. van Eijk · M. van Dongen

Institute of Psychology, Erasmus University Rotterdam, Rotterdam, The Netherlands
} 
increasingly aware of new diseases (e.g., AIDS), disasters (e.g., floods), and other threatening events (e.g., drugs) that may occur. Indeed, there is evidence from experimental studies demonstrating that negative information about stimuli and situations may install fear in children (Field et al. 2001; Muris et al. 2003).

Terrorism certainly poses a serious threat to the Western society. In particular, the attacks on the World Trade Center on September 11, 2001 by Al Queda, Osama Bin Laden's radicalized Muslim grouping, have increased people's awareness of this contemporary danger. Research has shown that these events have likely increased fear and anxiety in American youths, and not only in those who were directly exposed to this traumatic event (Hoven et al. 2003). For example, a prospective study by Lengua et al. (2005) demonstrated that even some of the children who experienced the $9 / 11$ attacks indirectly via media exposure had developed significant fear and anxiety complaints.

The impact of terrorism on children's fear outside the United States has not been investigated, although it is clear that various countries run the risk of a terrorist attack as they are close allies of America in its 'war on terror.' Exemplary in this regard are the bombing attacks in Madrid on March 11, 2004 and London on July 7 and 21, 2005, which indicate that countries of which governments support the United States' anti-terrorism policy are indeed a target of Al Queda and related groupings. The Netherlands, being a faithful sympathizer of the United States, should also be regarded as a potential target of terrorist attacks. So far, a massive onslaught has not taken place in this European country, but smaller incidents such as the murder on the Dutch film-maker Theo van Gogh (who publicly criticized the Islam) by a Muslim radical and the arrest of the 'Hofstad' network, an Islamic terrorist organization of young Dutch Muslims, have demonstrated that this type of danger is also lurking for the population in The Netherlands. Acknowledging the terrorist threat, the Dutch government launched a national anti-terrorism campaign in the first month of 2006. Via adverts on television and radio, leaflets delivered to every house, posters throughout the cities, and announcements in public transport systems, the general public was warned for terrorists and instructed to report any suspicious activities to the police.

As mentioned earlier, it is largely unknown whether children in Western countries such as The Netherlands are affected by the threat of terrorism and actually fear stimuli and situations that are related to this type of danger. To examine this issue, we designed the present study. A large sample of school children living in Rotterdam or adjacent satellites $(N=216)$ were asked to complete a modified version of the Fear Survey Schedule for Children-Revised (FSSC-R; Ollendick 1983) that included a number of terrorism-related items (e.g., Osama Bin Laden, bombing attacks). In addition, an ambiguous vignette task was administered to the children for measuring threat-related interpretation bias. In one half of the children, the vignette task included a number of terrorist-relevant situations (e.g., Islamic man with heavy backpack walking in a shopping center). In the other half of the children, the vignette task was modified in such way that the situations did not refer to possible terrorist activities. In this way, it became possible to examine whether (1) terrorism-related items rank high in a fear ranking based on the 
FSSC-R, and (2) children interpret ambiguous, potentially terrorist-relevant situations in a threatening way.

\section{Method}

Participants and Procedure

Participants were 216, 9- to 13-year-old children (104 boys and 112 girls; mean age $=10.88$ years, $S D=0.95$ ) recruited from four primary schools in Rotterdam, Spijkenisse, and Ridderkerk, The Netherlands. This was done by sending their parents an informed consent letter. More than $90 \%$ of the children who were approached eventually participated in the study. A small majority of the children had an original Dutch background (i.e., 52.8\%), the others were from non-Caucasian descent and a substantial proportion of them came from Islamic countries $(30.1 \%$; e.g., Turkish, Moroccan, Afghanistan). No exact information on the socio-economic status of the children was available, but it should be mentioned that these children were recruited from an urban region in which most people had a low to middle socio-economic background.

Children were tested on two separate occasions, some 2 weeks apart. On the first occasion the modified FSSC-R was completed, while on the second occasion the vignette task was administered. Within each class, one half of the children received a version including terrorist-relevant vignettes, whereas the other half was given a terrorist-neutral version of the vignette task.

\section{Questionnaires}

\section{Modified FSSC-R}

The original FSSC-R (Ollendick 1983) is an 80-item self-report questionnaire for assessing fears and fearfulness in children. Children are asked to indicate their level of fear to various stimuli and situations on a 3-point scale: 'none,' 'some,' 'a lot.' These are scored 1,2, and 3, respectively, and then summed to yield a total fear score and/or five factor-based fear scores referring to the categories of danger and death, the unknown, failure and criticism, minor injury and small animals, and medical affairs. In an attempt to develop a more 'modern' version of the scale, a number of modifications were carried through by Shore and Rapport (1998; see Muris and Ollendick 2002). That is, some items were deleted from the scale because they seem less relevant nowadays (e.g., Russia), whereas various new items were included in order to measure fear of contemporary threatening stimuli and situations, such as school violence, sexual assaults, domestic violence, parental divorce, and AIDS. Research has demonstrated that these modifications of the FSSC-R have not negatively influenced the psychometric properties of the scale (Shore and Rapport 1998; Muris and Ollendick 2002). 
For the purpose of the present study, eight new items were added to the FSSC-R in an attempt to measure children's fear of terrorism: 'women with veils,' 'bombing attacks,' 'explosions in the bus or subway,' 'Mohammed B.' (i.e., Theo van Gogh's assassin), 'terrorists,' 'Osama Bin Laden,' 'pictures of airplanes crashing into buildings,' and 'Muslims burning the American flag.' Two items (i.e., 'being raped' and 'myself dying') were removed from the modified FSSC-R because one of the school boards found them not appropriate for school children of this age. Reliability coefficients for the modified version of the FSSC-R appeared to be satisfactory, with a Cronbach's alpha of .82 for the fear of terrorism subscale and .97 for the total score (excluding fear of terrorism items).

\section{Vignette Task}

A series of ambiguous vignettes were employed to assess threat-related interpretation bias (see Muris et al. 2000). There were nine vignettes, with three vignettes referring to each category: social threat, general threat, and terrorism threat/control (see Table 1). The social threat and general threat vignettes were similar for all children, while the third category differed across participants. That is, for only half of the children ( $n=108)$, the vignette task included a number of terrorism-relevant situations (i.e., Islamic man with heavy backpack walking in a shopping center, a group of women with veils traveling in the subway, and two men coming out of a mosque while mysteriously whispering to each other; i.e., experimental condition). For the other half of the children $(n=108)$, these vignettes were modified in such way that the situations did not refer to possible terrorist activities (i.e., control condition; see for an example Table 1). Children were instructed to read each of the vignettes carefully and then to briefly write down what was going to happen in the pertinent scenario. These interpretations were scored by two raters who decided (1) whether children perceived any threat in the scenario (i.e., threat interpretation), and (2) whether the perceived threat had any relationship with terrorism (i.e., terrorist interpretation). Analysis of the inter-rater agreement based on 30 randomly selected children (15 of each rater) indicated that the reliability of both scores was

Table 1 Examples of vignettes that were used in this study to measure threat-related interpretation bias

\begin{tabular}{ll}
\hline Social threat & $\begin{array}{l}\text { It's your first day on a new school. You don't know any of the children in your } \\
\text { new class. The teacher introduces you to the class and then says that you should } \\
\text { give an oral report next week ... }\end{array}$ \\
General threat $\quad \begin{array}{l}\text { You have stayed over for dinner with one of your friends. Now you have to walk } \\
\text { home. It's a couple of miles and it is already starting to get dark ... }\end{array}$ \\
Terrorism threat $\quad \begin{array}{l}\text { You are walking in a shopping center. There you see a man walking with a heavy } \\
\text { backpack. He is wearing black clothes and the text on his t-shirt says: My name } \\
\text { is Hassan ... }\end{array}$ \\
$\begin{array}{l}\text { You are walking in a shopping center. There you see a man walking with a heavy } \\
\text { backpack. He is wearing black clothes and the text on his t-shirt says: My name } \\
\text { is Peter ... }\end{array}$
\end{tabular}


satisfactory: Cohen's kappa was .80 for threat interpretation and 1.00 for terrorist interpretation.

\section{Results}

\section{General Findings}

Before addressing the main research issues of the present study, a number of general results are discussed. First of all, in keeping with previous research, girls displayed higher fear scores than boys (see for a review Gullone 2000), and this was not only the case for FSSC-R total scores [means being 140.00, $S D=26.01$ vs. $115.49, S D=21.64 ; t(214)=7.50, p<.001]$ but also for FSSC-R fear of terrorism scores [means being 15.72, $S D=3.36$ vs. 13.36, $S D=4.02 ; t$ $(214)=4.71, p<.001]$. Second, children with an original Dutch background displayed higher fear of terrorism scores $(M=15.19, S D=4.10)$ than children with an Islamic background $(M=13.54, S D=3.61 ; t(177)=2.71, p<.01)$. As a more stringent test, a 2 (Gender) $\times 2$ (Background) analysis of variance (ANOVA) with total FSSC-R scores as a covariate was carried out. This analysis indicated that the difference in fear of terrorism scores between children from a Dutch and an Islamic origin remained significant $(F(1,174)=30.47, p<.001)$. Third, no such effects of cultural background on threat and terrorist interpretation scores were found (both $t(177) \mathrm{s}<1.10)$. Fourth and finally, correlations computed between FSSC-R and interpretation bias scores revealed a significant association between total fear score and general threat interpretation $(r=.20$, $p<.05$ ), indicating that children with higher fear scores were more inclined to interpret the ambiguous situations as threatening. No such a relation was observed between children's fear (as indexed by FSSC-R total and fear of terrorism scores) and terrorist interpretation scores.

\section{Terrorism Items in Fear Ranking}

A fear ranking was obtained by calculating mean scores for individual FSSC-R items (see Ollendick 1983). The results generally revealed the commonly found rank order which indicates that in particular fear of danger and death items were most prevalent among children (Ollendick et al. 1989; Muris and Ollendick 2002; King et al. 1989). Interestingly, we found that two terrorism-related items ranked in the top 10 of most intense fears, namely 'bombing attacks' (position 6) and 'explosions in the bus or subway' (position 7). Other terrorism-related items ranked considerably lower: 'terrorists' (18th), 'Osama Bin Laden' (21th), 'Mohammed B.' (31th), 'pictures of airplanes crashing into buildings' (47th), 'Muslims burning the American flag' (55th), and 'women with veils' (87th). 


\section{Threat and Terrorist Interpretations}

Table 2 displays mean threat and terrorist interpretation scores in response to various types of vignettes in both conditions. A 2 (Gender) $\times 2$ (Condition: experimental versus control) $\times 2$ (Interpretation: threat versus terrorist) ANOVA with the last factor being a within-subjects variable performed on the total interpretation scores, only yielded a significant effect of interpretation ( $F$ $(1,212)=109.23, p<.001)$. Not surprisingly, threat interpretations were more frequently made by the children than terrorist interpretations, which in fact were fairly infrequent.

A further 2 (Gender) $\times 2$ (Condition) $\times 3$ (Vignette: social threat versus general threat versus control/terrorist threat) ANOVA carried out on the threat interpretation scores did not yield any significant effects. A similar ANOVA performed on terrorist interpretation scores only revealed that there was a significant main effect of vignette $(F(1,212)=5.67, p<.05)$. As can be seen in Table 2 , children only made terrorist-related interpretations in response to terrorism threat and control threat vignettes.

\section{Discussion}

The present study was a first attempt to investigate to what extent children in The Netherlands are affected by the threat of Islamic terrorism. On the one hand, the data of the fear survey indicated that a number of terrorism-related items (i.e., bombing attacks, explosions in a bus or subway) were listed high in a ranking of most intense childhood fears. On the other hand, the results of the vignette task, which intended to measure threat-related interpretation bias, demonstrated that children rarely made terrorist-related interpretations of ambiguous situations.

Table 2 Mean threat and terrorist interpretation scores (standard deviations) in response to various types of vignettes

\begin{tabular}{lll}
\hline & Threat interpretation & Terrorist interpretation \\
\hline $\begin{array}{l}\text { Experimental condition } \\
\text { Total threat }\end{array}$ & $1.06(1.59)$ & $0.05(0.25)$ \\
Social threat & $0.34(0.64)$ & $0.00(0.00)$ \\
General threat & $0.35(0.67)$ & $0.00(0.00)$ \\
Terrorist threat & $0.37(0.69)$ & $0.05(0.25)$ \\
Control condition & & \\
Total threat & $1.06(1.38)$ & $0.02(0.14)$ \\
Social threat & $0.33(0.61)$ & $0.00(0.00)$ \\
General threat & $0.31(0.59)$ & $0.00(0.00)$ \\
Control threat & $0.43(0.74)$ & $0.02(0.14)$ \\
\hline
\end{tabular}

Note: $n=108$ for each condition 
How to reconcile these somewhat conflicting results? In this regard, it may be important to mention that several authors have pointed out that fear of danger and death items in the FSSC-R do not really assess the frequency of actual fearful behavior and thoughts, but rather index the negative affective response to the thought of the possible occurrence of these specific events (McCathie and Spence 1991; Muris et al. 2002a). Direct evidence for this notion was obtained by Muris et al. (2002b) who employed a diary method to demonstrate that highly ranked FSSC-R danger and death items actually had a low probability of occurrence and intensity in daily life. In other words, it may well be the case that the children in the current study were not really bothered by fears of bombing attacks and explosions in public transport, but rather indicated how threatening such events would be in case they would happen to them. Otherwise, it can be argued that the vignette task was not sensitive enough to tap children's threat-related interpretation bias. Note that this explanation is not very likely: children certainly made negative interpretations in response to the ambiguous vignettes (including those describing scenarios that could be related to terrorist activities), and these interpretations were also significantly associated with children's fear scores (see for an overview of interpretation bias studies in youths: Vasey and MacLeod 2001). The fact, however, is that children rarely made terrorism-related interpretations, even when the vignettes included cues (e.g., Islamic man, women with veils, mosque) that were meant to prime children in this direction. Altogether, it seems most plausible to conclude that Dutch children (at least those included in the present study) are not really affected by the world-wide threat of terrorism.

An additional finding of the current study was that children with an original Dutch background displayed higher fear of terrorism scores than children with an Islamic background. This has probably to do with the fact that the Muslim youths probably have a more realistic picture of the Islam and the (fairly small) chance that an Islamic individual would undertake terrorist activities, whereas for native Dutch children it is rather difficult to judge the probability that an average Islamic individual would engage in such activities.

Admittedly, this study suffered from various limitations. First of all, the research was conducted in an urban area (Rotterdam) in which children are very familiar with non-Caucasian communities, including people with an Islamic background. It may well be the case that fear of terrorism is more pronounced in Dutch children living in the more rural parts of the country. On the other hand, the chance that a terrorist attack will take place in a city like Rotterdam is of course more likely than that it will occur in some town in the provinces. Second, the study was carried out more than half a year after the last serious terrorist activities in a Western country (in London, July 2005), and so it may well be that the threat of terrorism had diminished and children's fears for such events were abated. It is also possible that the children found it reassuring that the Dutch government had just started the national anti-terrorism campaign, which perhaps gave them the (naïve) idea that the danger was under control.

Altogether, the conclusion seems justified that Dutch children are not really affected by the threat of terrorism and actually show little fear of stimuli and situations that are related to this type of danger. It's hoped that a serious terrorist 
attack can be prevented in The Netherlands, so that this state of affairs is not going to change in the future.

Acknowledgment The authors kindly thank a 10-year-old boy who came up with the statement "I'm not really afraid of Osama Bin Laden!" (which was used for the title of this article) when talking with him about fear of terrorism in The Netherlands.

Open Access This article is distributed under the terms of the Creative Commons Attribution Noncommercial License which permits any noncommercial use, distribution, and reproduction in any medium, provided the original author(s) and source are credited.

\section{References}

Field, A. P., Argyris, N. G., \& Knowles, K. A. (2001). Who's afraid of the big bad wolf: A prospective paradigm to test Rachman's indirect pathways in children. Behaviour Research and Therapy, 39, 1259-1276.

Fishkin, S. A., Rohrbach, L. A., \& Anderson-Johnson, C. (1997). Correlates of youths'fears of victimization. Journal of Applied Social Psychology, 27, 1601-1616.

Gullone, E. (2000). The development of normal fear: A century of research. Clinical Psychology Review, 20, 429-451.

Hoven, C. W., Mandell, D. J., \& Duarte, C. S. (2003). Mental health of New York city public school children after 9/11: An epidemiologic investigation. In S. W. Coates, J. L. Rosenthal, \& D. S. Schechter (Eds.), September 11: Trauma and human bonds (pp. 51-74). Hillsdale: Analytic Press.

King, N. J., Ollier, K., Iacuone, R., Schuster, S., Bays, K., Gullone, E., \& Ollendick, T. H. (1989). Fears of children and adolescents: A cross-sectional Australian study using the revised fear survey schedule for Children. Journal of Child Psychology and Psychiatry, 30, 775-784.

Lengua, L. J., Long, A. C., Smith, K. I., \& Meltzoff, A. N. (2005). Pre-attack symptomatology and temperament as predictors of children's responses to the September 11 terrorist attacks. Journal of Child Psychology and Psychiatry, 46, 631-645.

McCathie, H., \& Spence, S. H. (1991). What is the revised fear survey schedule for children measuring? Behaviour Research and Therapy, 29, 495-502.

Muris, P., Bodden, D., Merckelbach, H., Ollendick, T. H., \& King, N. J. (2003). Fear of the beast: A prospective study on the effects of negative information on childhood fear. Behaviour Research and Therapy, 41, 195-208.

Muris, P., Kindt, M., Bögels, S., Merckelbach, H., Gadet, B., \& Moulaert, V. (2000). Anxiety and threat perception abnormalities in normal children. Journal of Psychopathology and Behavioral Assessment, 22, 183-199.

Muris, P., Meesters, C., Merckelbach, H., Verschuren, M., Geebelen, E., \& Aleva, E. (2002a). Fear of storms and hurricanes in Antillean and Belgian children. Behaviour Research and Therapy, 40, 459-469.

Muris, P., Merckelbach, H., Ollendick, T. H., King, N. J., Meesters, C., \& Van Kessel, C. (2002b). What is the revised fear survey schedule for children measuring? Behaviour Research and Therapy, 40, 1317-1326.

Muris, P., \& Ollendick, T. H. (2002). The assessment of contemporary fears in adolescents using a modified version of the fear survey schedule for children-revised. Journal of Anxiety Disorders, $16,567-584$.

Ollendick, T. H. (1983). Reliability and validity of the revised fear survey schedule for children (FSSCR). Behaviour Research and Therapy, 21, 685-692.

Ollendick, T. H., King, N. J., \& Frary, R. B. (1989). Fears in children and adolescents: Reliability and generalizability across gender, age, and nationality. Behaviour Research and Therapy, 27, 19-26.

Shore, G. N., \& Rapport, M. D. (1998). The fear survey schedule for children-revised (FSSC-HI): Ethnocultural variations in children's fearfulness. Journal of Anxiety Disorders, 12, 437-461.

Vasey, M. W., \& MacLeod, C. (2001). Information-processing factors in childhood anxiety: A review and developmental perspective. In M. W. Vasey \& M. R. Dadds (Eds.), The developmental psychopathology of anxiety (pp. 253-277). New York: Oxford University Press. 